\title{
Biogeography of the two major arbovirus mosquito vectors, Aedes aegypti and Aedes albopictus (Diptera, Culicidae), in Madagascar
}

Fara Nantenaina Raharimalala 1,2, Lala Harivelo Ravaomanarivo², Pierre Ravelonandro ${ }^{3}$, Lala Sahondra Rafarasoa ${ }^{2}$, Karima Zouache ${ }^{1}$, Van Tran-Van', Laurence Mousson4, Anna-Bella Failloux ${ }^{4}$, Eléonore Hellard ${ }^{5}$, Claire Valiente Moro ${ }^{1}$, Bakoly Olga Ralisoa ${ }^{2}$ and Patrick Mavingui ${ }^{1,6^{*}}$

\begin{abstract}
Background: In the past ten years, the Indian Ocean region has been the theatre of severe epidemics of chikungunya and dengue. These outbreaks coincided with a high increase in populations of Aedes albopictus that outcompete its sister taxon Aedes aegypti in most islands sampled. The objective of this work was to update the entomological survey of the two Aedes species in the island of Madagascar which has to face these arboviroses.

Methods: The sampling of Aedes mosquitoes was conducted during two years, from October 2007 to October 2009, in fifteen localities from eight regions of contrasting climates. Captured adults were identified immediately whereas immature stages were bred until adult stage for determination. Phylogenetic analysis was performed using two mtDNA genes, COI and ND5 and trees were constructed by the maximum likelihood (ML) method with the gene time reversible (GTR) model. Experimental infections with the chikungunya virus strain 06.21 at a titer of $10^{7.5} \mathrm{pfu} / \mathrm{mL}$ were performed to evaluate the vector competence of field-collected mosquitoes. Disseminated infection rates were measured fourteen days after infection by immunofluorescence assay performed on head squashes.
\end{abstract}

Results: The species Aedes aegypti was detected in only six sites in native forests and natural reserves. In contrast, the species Aedes albopictus was found in 13 out of the 15 sites sampled. Breeding sites were mostly found in man-made environments such as discarded containers, used tires, abandoned buckets, coconuts, and bamboo cuts. Linear regression models showed that the abundance of Ae. albopictus was significantly influenced by the sampling region $\left(F=62.00, p<2.2 \times 10^{-16}\right)$ and period $\left(F=36.22, p=2.548 \times 10^{-13}\right)$, that are associated with ecological and climate variations. Phylogenetic analysis of the invasive Ae. albopictus distinguished haplotypes from South Asia and South America from those of Madagascar, but the markers used were not discriminant enough to discern Malagasy populations. The experimental oral infection method showed that six Ae. albopictus populations exhibited high dissemination infection rates for chikungunya virus ranging from 98 to $100 \%$.

Conclusion: In Madagascar, Ae. albopictus has extended its geographical distribution whereas, Ae. aegypti has become rare, contrasting with what was previously observed. Changes are predominantly driven by human activities and the rainfall regime that provide suitable breeding sites for the highly anthropophilic mosquito Ae. albopictus. Moreover, these populations were found to be highly susceptible to chikungunya virus. In the light of this study, Ae. albopictus may have been involved in the recent outbreaks of chikungunya and dengue epidemics in Madagascar, and consequently, control measures should be promoted to limit its current expansion.

\footnotetext{
* Correspondence: patrick.mavingui@univ-lyon1.fr

'UMR CNRS 5557 Ecologie Microbienne, Université Lyon 1, 43 boulevard du

11 Novembre 1918, Villeurbanne cedex 69622, France

Full list of author information is available at the end of the article
} 


\section{Background}

Among the 29 mosquito species of the genus Aedes reported in Madagascar, thirteen are endemic [1]. Since the reports in the 1980s [1,2], no extensive survey has been conducted on the geographical distribution of the Aedes genus in Madagascar. As Aedes species are major vectors of arboviral diseases, the control of these mosquitoes is needed to prevent or limit the epidemic risks. Recently, the species Aedes aegypti and Aedes albopictus have been involved in arbovirus outbreaks worldwide [3-5]. During the last ten years, the Indian Ocean Islands have witnessed severe epidemics of arboviruses, notably chikungunya (CHIK) and dengue (DEN). In contrast to the $1950 \mathrm{~s}$ when Ae. aegypti was involved as the main vector $[6,7]$, the species Ae. albopictus has been identified as the primary vector of most recent outbreaks in the Indian Ocean [8-12].

In Madagascar, outbreaks of DEN and CHIK fevers emerged in the east coast of Toamasina on January 2006 [11]. Since then, several cases of CHIK and DEN were reported in different regions of Madagascar, including Antalaha (north-east coast), Antsiranana (north coast), Mahajanga (north-west coast) and Toamasina (east coast) [13], (http://www.invs.sante.fr). During these epidemics, the species Ae. albopictus was identified as the main vector $[5,11,14]$. These data are in line with what is known on the current worldwide expansion of Ae. albopictus, which outcompetes its sister taxon Ae. aegypti [15-18].

The goal of this study was to survey populations of $A e$. aegypti and Ae. albopictus of Madagascar and to explore whether their geographical distribution has evolved. Entomological investigations were conducted in eight regions where various sites were visited. The choice of the areas to sample was based on at least one of the following elements (i) existence of previous records of the genus Aedes spp, (ii) contrasted ecoclimatic characteristics, and (iii) suspected or confirmed human cases of CHIK and/or DEN during recent outbreaks in the region $[11,13,19]$. Collected adults and immature stages were genetically characterized by haplotyping, and susceptibility to arboviruses was measured in a biosafety laboratory level 3 .

\section{Methods}

\section{Geographic location and characteristics of study areas}

Ae. albopictus and Ae. aegypti were sampled in cities, villages, natural reserves and forests in eight regions of Madagascar (Figure 1). The characteristics of the sampled areas are summarized in Table 1 and Figure 2. The Analamanga region is located in the highlands of Madagascar at an altitude of $1200-1433 \mathrm{~m}$, with a tropical climate. In this area, two seasons are observed: a hot $\left(21^{\circ} \mathrm{C}\right.$ on average) and rainy period (November to April with about 200 $\mathrm{mm}$ precipitation in a month), and a relatively dry cool season for the rest of the year $\left(10^{\circ} \mathrm{C}\right.$ on average and

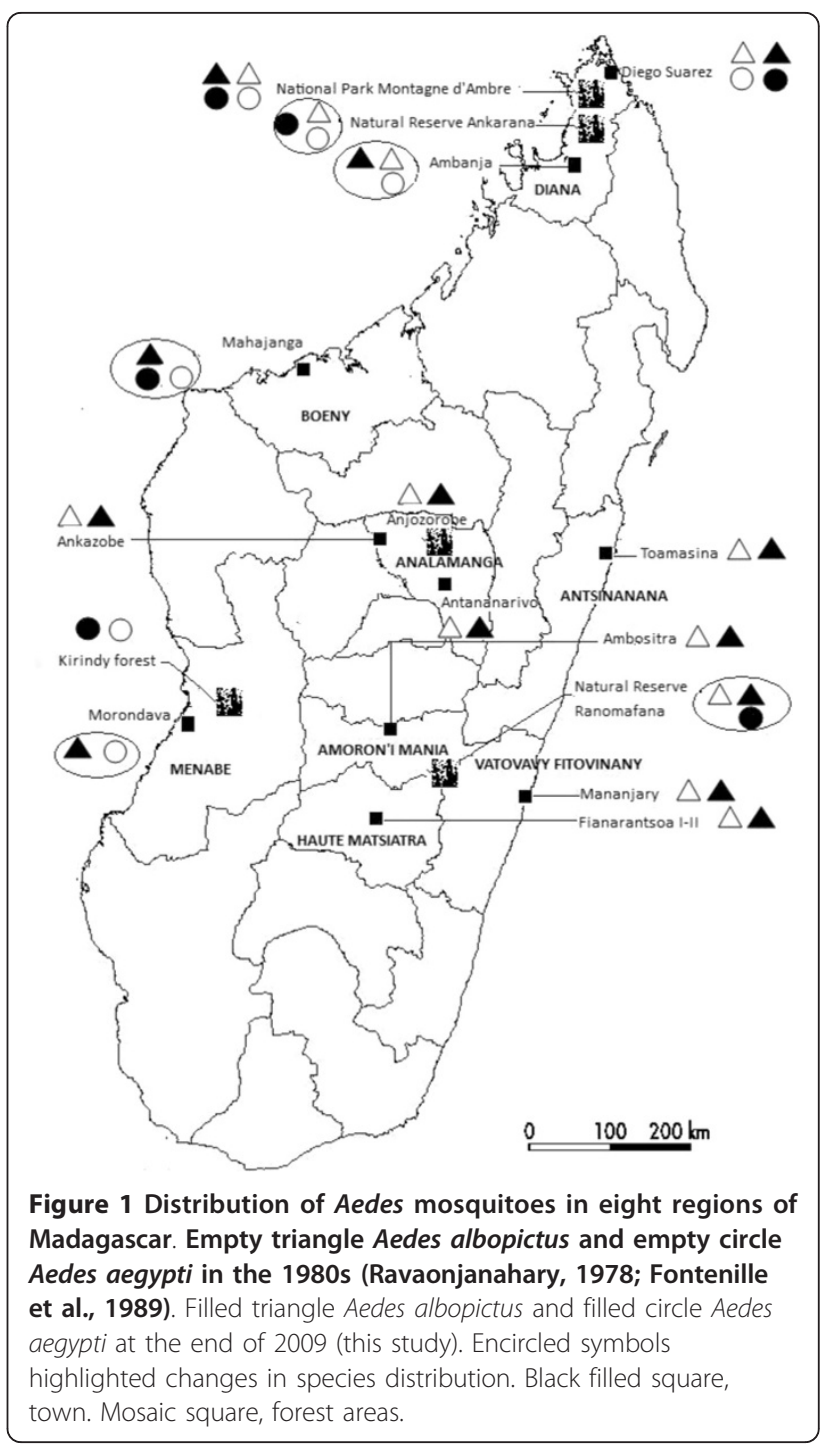

rainfall not exceeding $20 \mathrm{~mm}$ precipitation in a month). The Zoological and Botanic Park of Tsimbazaza is located in the Center of Antananarivo at $1200 \mathrm{~m}$ altitude. As Analamanga region, Amoron'i Mania region (Ambositra) and Haute Matsiatra region (Fianarantsoa) are also in the highlands of Madagascar and have similar features. Ranomafana forest is situated in a region between Amoron'i Mania and Vatovavy Fitovinany in the western side of Madagascar. The climate is tropical, humid and rainy (with an annual rainfall of $2600 \mathrm{~mm}$ ) and the temperature varies from 14 to $20^{\circ} \mathrm{C}$. The Antsinanana region (Toamasina, Foulpointe) is in the eastern plains of the island. The climate is hot and wet and rains occur all the year with the mean annual rainfall of about $3200 \mathrm{~mm}$ and a relative humidity around $87 \%$.

The Boeny region (Mahajanga) is located in the western plains. It has an equatorial climate with an arid and warm summer (mean temperature of $27^{\circ} \mathrm{C}$ ) with moderate 
Table 1 Ecological characteristics of sampling areas

\begin{tabular}{|c|c|c|c|c|}
\hline Areas & Regions & Sites & Adult breeding sites & Larval habitats \\
\hline \multirow[t]{6}{*}{ Highlands } & Analamanga & Antananarivo city & Bamboo & Bamboo hedge, discarded containers \\
\hline & & Anjozorobe forest & Bamboo, bushes & Bamboo hedge \\
\hline & & Ankazobe village & Bushes & Bamboo hedge, used tires \\
\hline & Amoron'i Mania & Ambositra city & $\begin{array}{l}\text { Fruit trees, bamboo, } \\
\text { bushes }\end{array}$ & Bamboo hedge, used tires \\
\hline & & $\begin{array}{l}\text { Ranomafana village, } \\
\text { forest }\end{array}$ & Bushes & Discarded containers, hollow roks \\
\hline & Haute Matsiatra & Fianarantsoa I-II city & Mango trees, bushes & Discarded containers, used tires \\
\hline Eastern Plains & Antsinanana & Toamasina city in coast & Bamboo hedge, bushes & $\begin{array}{l}\text { Abandoned buckets, used tires, drum, } \\
\text { coconut }\end{array}$ \\
\hline \multirow[t]{3}{*}{ Western Plains } & Boeny & Mahajanga city in coast & Mango trees, bushes & Discarded containers, used tires \\
\hline & Menabe & Morondava city in coast & Mango trees, bushes & $\begin{array}{l}\text { Abandoned buckets, used tires, drum, } \\
\text { coconut }\end{array}$ \\
\hline & & Kirindy forest & Forest & Hollow rocks, tree holes \\
\hline Southeast Coast & $\begin{array}{l}\text { Vatovavy } \\
\text { Fitovinany }\end{array}$ & Mananjary city in coast & Fruit trees, bushes & $\begin{array}{l}\text { Bamboo hedge, discarded containers, } \\
\text { coconut }\end{array}$ \\
\hline \multirow[t]{4}{*}{$\begin{array}{l}\text { North Plains - North } \\
\text { West }\end{array}$} & Diana & Ambanja city & Bushes & $\begin{array}{l}\text { Abandoned buckets, used tires, drum, } \\
\text { coconut }\end{array}$ \\
\hline & & Ankarana forest & Forest & Hollow rocks, tree holes \\
\hline & & $\begin{array}{l}\text { Montagne d'Ambre } \\
\text { forest }\end{array}$ & Forest & Hollow rocks, tree holes \\
\hline & & $\begin{array}{l}\text { Diego Suarez city in } \\
\text { coast }\end{array}$ & Bushes, fruit trees & $\begin{array}{l}\text { Abandoned buckets, used tires, drum, } \\
\text { coconut }\end{array}$ \\
\hline
\end{tabular}

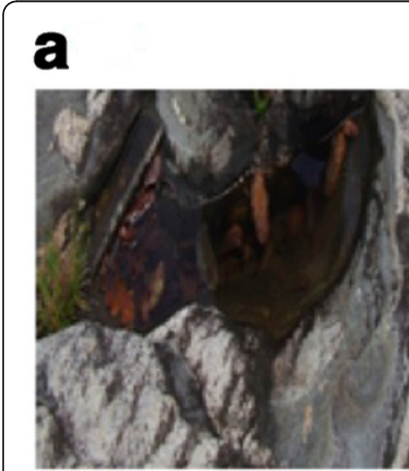

hollow rocks

b

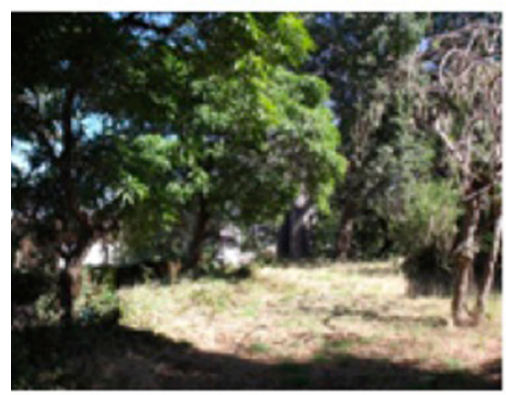

mango trees

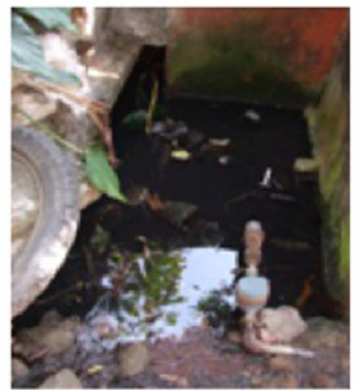

puisard

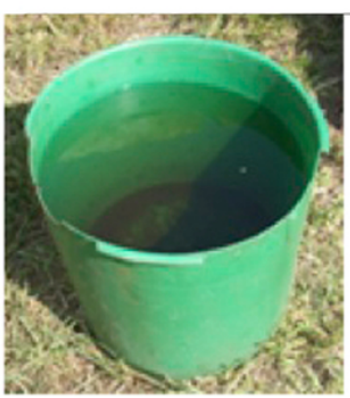

bucket abandonned

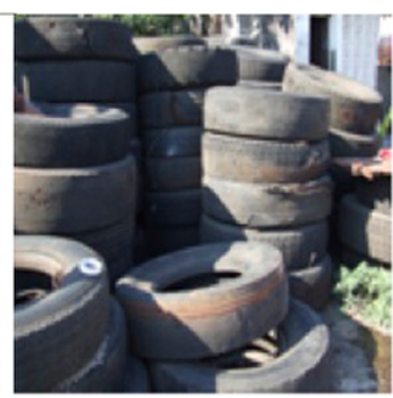

used tíres

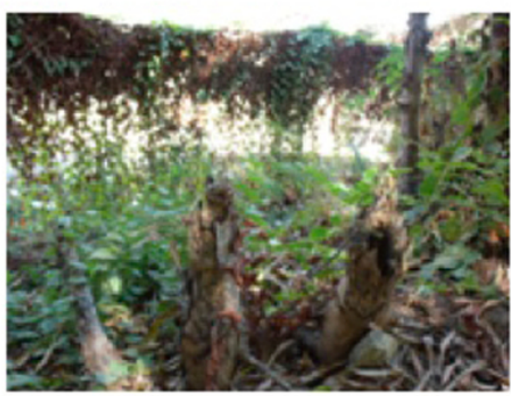

bushes

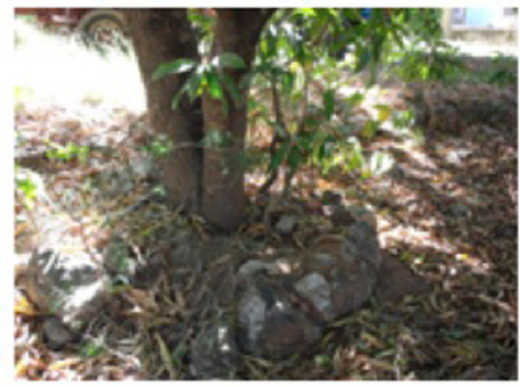

fruits trees

Figure 2 View of mosquito breeding sites. A: sites of immature stages; B: sites of adults 
rainfall (the mean precipitation is about $400 \mathrm{~mm}$ per year). The Menabe region (Morondava, Kirindy forest) is also situated in the western plains. It has a similar climate to the Boeny region. However, the temperature can reach more than $40^{\circ} \mathrm{C}$ during the rainy season (late December until the end of March). Rainfall is not constant during this period but spaced with dry periods.

The Vatovavy-Fitovinany region (Mananjary) is in the southwest coast of Madagascar and has a tropical climate along the coast, is temperate inland and arid in the south. The Diana region is situated in the northwestern plains of Madagascar, where the sampling sites of Diego-Suarez and Ambanja cities are located, as well as the reserved forests of Ankarana and Montagne d'Ambre. The climate is equatorial dry and this area is situated between $4 \mathrm{~m}$ altitude (Ankarana) and $1400 \mathrm{~m}$ (Montagne d'Ambre). It is characterized by an alternation of wet and dry seasons (May to November) and a hot and humid season (December to April). The average temperature is $27^{\circ} \mathrm{C}$ and rainfall varies from 985 to 2171 mm per year.

\section{Collection and processing of mosquitoes}

Adults and immature stages of mosquitoes were collected monthly from October 2007 to October 2009 in 8 regions corresponding to a total of 15 different sites (Figure 2). In each site, collections were performed daily over a period of one week by visiting three to four spots previously identified as hosting adult breeding sites and larval habitats of Aedes (Table 1). The same spots were visited, unless changes occurred due to human activities, thus obliging capturers to search for other potential new breeding sites and habitats in the area. As Aedes albopictus and Aedes aegypti are diurnal mosquitoes, adults were collected during the two peaks of biting activities, i.e. 7:00 to $10: 30$ am and 15:30 to $18: 00 \mathrm{pm}$. Two methods were used to catch adult mosquitoes. The first method consisted of the use of butterfly nets that allows collection of both females and males flying near the grass. This was done by applying ten rounds of netting near the grassland and underneath bushes, bamboo and fruit trees. Then, capturers moved to another site. The second method was performed using oral aspirators to capture host-seeking females landing on the legs of human volunteer-baits who gave their agreement. Malagasy administrative authorities, particularly Madagascar National Parks (formely ANGAP), were informed and approved mosquito collections which were conducted in conformity to the declaration of Helsinky on ethical principles for medical research involving human subjects. To avoid biting, three capturers performed collection at one time. Exposed legs of one volunteer were under monitoring of two nonexposed capturers who catch mosquitoes immediately after landing. When trapping in an area, capturers spent
15 to $30 \mathrm{~min}$ at one spot then moved to another. Each spot was visited twice during each peak of biting activity. Collected adult mosquitoes were stored in cups covered with netting. Aedes spp. specimens were identified morphologically [1], then males and females were separately desiccated, in silicagel. In order to keep some individuals alive during transfer to the laboratory, impregnated cotton with $6 \%$ sucrose solution was placed at their disposal. Larval habitats consisted of artificial containers and natural sites containing standing water (Table 1). When larvae and pupae were present, they were collected using a dipper and transferred to a plastic bottle using a widemouthed pipette. Collected specimens were brought back to the laboratory where they were reared until adult stage and then identified. Usually, larvae and pupae were sampled at the same time as adults. For each species, the number of individuals, date of capture and location site were recorded.

\section{Mosquito infection and virus dissemination rate measurement}

Wild-caught females were blood-fed on chickens and allowed to lay their eggs on absorbent paper in insectaries under standard conditions $\left(28^{\circ} \mathrm{C} \pm 2^{\circ} \mathrm{C}, 80 \% \pm 12 \%\right.$ humidity, photoperiod: $12 \mathrm{~h} / 12 \mathrm{~h}$ ) in Madagascar. Batches of eggs were brought to biosafety insectaries in the Pasteur Institute in Paris using a safety transport procedure. After hatching, larvae were reared to adults in standard conditions as described [20].

To infect mosquitoes, two independent experiments were carried out at an interval of three months with the same batches of eggs. The strain CHIKV (E1-226 V), which has an A- $>\mathrm{V}$ amino acid substitution at position 226 in the E1 glycoprotein, was used [8]. Virus stock and mosquito infection were performed as described $[9,20]$. Briefly, $1 \mathrm{~mL}$ of viral suspension was added to $2 \mathrm{~mL}$ of washed rabbit erythrocytes supplemented with ATP $(5 \times$ $\left.10^{-3} \mathrm{M}\right)$ as a phagostimulant. The resulting infectious blood at a titer of $10^{7.5} \mathrm{PFU} / \mathrm{mL}$ was transferred to a glass feeder at $37^{\circ} \mathrm{C}$ on top of the mesh covering a plastic box containing female mosquitoes from each of the six populations that were previously starved for $24 \mathrm{~h}$. After $15 \mathrm{~min}$ of oral feeding, mosquitoes were sorted on ice. Fully engorged females were transferred to cardboard containers then fed with $10 \%$ sucrose at $28^{\circ} \mathrm{C}$ for 14 days. After the incubation period, disseminated infection rates of CHIKV were determined (using surviving live mosquitoes), by immunofluorescence assay (IFA) on head squashes as described [21]. In brief, mosquito heads were placed between two glass slides and squashed by hand pressure. Squashed tissues were fixed by immersing in acetone for $20 \mathrm{~min}$ at $20^{\circ} \mathrm{C}$, then incubated with a first antibody, antiCHIKV diluted in PBS $1 \mathrm{X}(1: 200)$; the antibody was obtained from a mouse ascite. After incubation for $30 \mathrm{~min}$ 
at $37^{\circ} \mathrm{C}$, slides were washed three times in PBS $1 \mathrm{X}$ and incubated with an anti-mouse conjugate diluted in PBS $1 \mathrm{X}$ (1:80) and supplemented with Evan blue. Slides were observed under an epifluorescence microscope (Leitz, Larbolux K). In positive samples, the head tissue appeared in green whereas blue-colored tissue is negative. Therefore, the disseminated infection rate corresponds to the ratio between positive heads to the total number of surviving individuals examined.

\section{Nucleic acid extraction, PCR amplification and sequencing} To extract genomic DNA, five males and five females from each site were washed three times with sterilized water, then surface-disinfected with ethanol $80 \%$ for 5 min. After five washes with sterilized water, each individual mosquito was homogenized and the genomic DNA extracted using the procedure previously described [22].

For PCR, amplification was performed using a T Gradient Thermocycler (Biometra, France) with the primers targeting two mtDNA gene fragments: a 597-bp fragment of COI (cytochrome-oxydase subunit 1) and a 450-bp fragment of ND5 (NADH dehydrogenase subunit 5). The two sets of primers used were: for COI, CI-J-1632 (5'-TGATCAAATTTATAAT-3') and CI-N-2191 (5'-GGTAAAATTAAAATATAAACTTC-3') [23]; and, for ND5, ND5FOR (5'-TCCTTAGAATAAAATCCCGC-3') and ND5REV (5'GTTTCTGCTTTAGTT-CATTCTTC-3') [24]. Reactions were made in $50 \mu \mathrm{l}$ volume containing $90 \mathrm{ng}$ of DNA template, $1 \times$ PCR buffer, $50 \mathrm{mM} \mathrm{MgCl} 2,10 \mu \mathrm{M}$ of each primer, $2 \mathrm{mM}$ of dNTP mix (INVITROGEN, France), $0.4 \mathrm{U}$ of Taq DNA polymerase (INVITROGEN, France). The temperature profile for ND5 consisted of an initial denaturation at $98^{\circ} \mathrm{C}$ for $2 \mathrm{~min}$, followed by 5 cycles of $95^{\circ} \mathrm{C}$ for $30 \mathrm{~s}, 45^{\circ} \mathrm{C}$ for $30 \mathrm{~s}, 72^{\circ} \mathrm{C}$ for $45 \mathrm{~s}$, then 25 cycles of $95^{\circ} \mathrm{C}$ for $30 \mathrm{~s}, 46^{\circ} \mathrm{C}$ for $45 \mathrm{~s}, 72^{\circ} \mathrm{C}$ for $45 \mathrm{~s}$, and a final extension at $72^{\circ} \mathrm{C}$ for $5 \mathrm{~min}$. For $\mathrm{COI}$ the amplification program consisted of an initial denaturation at $95^{\circ} \mathrm{C}$ for $5 \mathrm{~min}$, followed by 35 cycles of $97^{\circ} \mathrm{C}$ for $30 \mathrm{~s}, 40^{\circ} \mathrm{C}$ for $45 \mathrm{~s}$, and $72^{\circ} \mathrm{C}$ for $1 \mathrm{~min}$, and a final extension at $72^{\circ} \mathrm{C}$ for $5 \mathrm{~min}$ [25]. An aliquot of $10 \mu \mathrm{l}$ of each PCR product was subjected to electrophoresis on a $1 \%$ agarose gel at $50 \mathrm{~V}$ for $30 \mathrm{~min}$, then stained with ethidium bromide and photographed with Gel Doc 2000 system (BioRad, USA). When bands with expected size were visualized, the remaining PCR products (approximately $40 \mu \mathrm{l}$ ) were sent to sequencing at BIOFIDAL-DTAMB (FR BioEnvironment and Health, Lyon, France).

\section{Phylogenetic analysis}

The COI and ND5 gene fragments were sequenced in both strands and deposited in Genbank with accession numbers JN406654-JN406797, JN406804-JN406809, JN406822-JN406832, JN406839-JN406844. Sequences were then aligned with those of mosquitoes available in databases by using BioEdit and Multialn softwares. The two gene sequences were concatenated to improve the reliability of the phylogenetic analysis. Phylogenetic analysis was carried out by using the Seaview software (http://pbil.univ-lyon1.fr/software/seaview.html) based on maximun likelihood (ML), maximum parsimony (MP) and neighbor-joining (NJ) methods. Trees were then constructed with the general time reversible (GTR) model, and branch supports were estimated by bootstrapping with 1000 replicates.

\section{Statistical analysis}

The effects of the sampling region, year, period, main habitat type and presence of one mosquito species to the abundance of the other species were investigated using linear regression models. The variable "period" corresponded to subdivision in a three-months sampling period per year, which can be linked roughly to a more rainy season from October to March and a more dry season from April to September. The variable "area" was categorized as highlands, eastern plains, western plains, southeast coast, north plains and north east (Table 1). All possible models (with all subsets of variable numbers and combinations) were generated. A square transformation was applied to ensure the normality of the residuals. Due to the sample size, only the region*year interaction was tested. Area and region were never put together in a model because they were correlated. The most appropriate model was selected using the Akaike Information Criterion adjusted for small sample size (AICc, [26]). The models were ranked according to the smallest AICc differences (denoted $\triangle \mathrm{AICc}$ ) between the focal model and the lowest AICc model. When $\triangle \mathrm{AICc}$ was larger than 2, the model with the smallest AICc was selected. On the contrary, when $\triangle \mathrm{AICc}$ was smaller than 2 and models nested, the most parsimonious model was kept. When models were not nested but AICc smaller than 2 , both models were kept.

\section{Results}

\section{Distribution of Aedes in the sampled regions of Madagascar}

Immature stages and adults of Ae. albopictus predominated in most sampled sites (13 out of 15). During the 27 months of sampling, a total of 12,639 adults (9891 females and 2748 males) and 7891 immature specimens of Ae. albopictus were collected (Table 2). Aedes albopictus was found in diverse ecological areas, from highland to the coast and under contrasting climates from arid to humid. Breeding sites and habitats included natural and human-made environments. In contrast, the species $A e$. aegypti was found in very limited numbers as imago (269 females and 46 males) and was mostly confined to sylvatic zones (Ranomafana, Kirindy, Ankarana and Montagne d'Ambre forest), with only a few specimens also captured 
Table 2 Abundance of Aedes albopictus captured in sampling regions.

\begin{tabular}{|c|c|c|c|c|c|c|c|c|c|c|c|}
\hline \multirow{2}{*}{$\begin{array}{l}\text { Species } \\
\text { MonthsRegions }\end{array}$} & \multicolumn{11}{|c|}{ Aedes albopictus numbers* } \\
\hline & $\begin{array}{l}\text { Oct-Dec } \\
(2007)\end{array}$ & $\begin{array}{l}\text { Jan-Mar } \\
\text { (2008) }\end{array}$ & $\begin{array}{l}\text { Avr-Jun } \\
(2008)\end{array}$ & $\begin{array}{l}\text { Jul-Sept } \\
\text { (2008) }\end{array}$ & $\begin{array}{l}\text { Oct-Dec } \\
(2008)\end{array}$ & $\begin{array}{l}\text { Total2007- } \\
2008\end{array}$ & $\begin{array}{l}\text { Jan-Mar } \\
\text { (2009) }\end{array}$ & $\begin{array}{l}\text { Avr-Jun } \\
\text { (2009) }\end{array}$ & $\begin{array}{l}\text { Jul-Sept } \\
\text { (2009) }\end{array}$ & $\begin{array}{l}\text { Oct-Dec } \\
(2009)\end{array}$ & Total2009 \\
\hline Analamanga & 595 & 493 & 328 & 287 & 581 & 2284 & 553 & 242 & 237 & 511 & 1543 \\
\hline Amoron'i Mania & 64 & 72 & 12 & 15 & 73 & 236 & 68 & 32 & 24 & 103 & 226 \\
\hline Haute Matsiatra & 37 & 31 & 7 & 9 & 29 & 113 & 67 & 48 & 21 & 43 & 179 \\
\hline Antsinanana & 1021 & 923 & 116 & 178 & 899 & 3137 & 1549 & 256 & 197 & 1762 & 3764 \\
\hline Boeny & 279 & 213 & 106 & 84 & 249 & 931 & 253 & 142 & 137 & 211 & 743 \\
\hline Menabe & 122 & 88 & 39 & 21 & 171 & 441 & 101 & 91 & 65 & 180 & 437 \\
\hline $\begin{array}{l}\text { Vatovavy } \\
\text { Fitovinany }\end{array}$ & 687 & 586 & 268 & 216 & 682 & 2439 & 958 & 269 & 287 & 827 & 2341 \\
\hline Diana & 213 & 175 & 129 & 108 & 247 & 872 & 259 & 117 & 214 & 254 & 844 \\
\hline Total & & & & & & 10453 & & & & & 10077 \\
\hline
\end{tabular}

Data are grouped per three-months sampling period. *Aedes albopictus numbers corresponded to the total of wild adults collected from the field and immature stages collected from the field and emerged in the laboratory (both sexes).

in Diego Suarez city (Table 3). In some areas, the current distribution of the two species was significantly different from what was recorded in the 1980s (Figure 1). For instance, in Ambanja town (Diana region), the two species were reported to be sympatric, but during our investigation, only Ae. albopictus was found. This coincided with the extension of the urbanization zone and an increase of man-made breeding sites. Interestingly, a converse pattern was observed in neighbouring villages of Ankarana where the sympatry was substituted by the allopatry of Ae. aegypti. In the same line, Ae. aegypti has recently colonized the natural reserve of Ranomafana, whereas Ae. albopictus has extensively invaded the cities of Mahajanga (Boeny region) and Morondava (Menabe region).

As Ae. albopictus has expanded since the 1980's in Madagascar and now predominated in most sampled sites, further analyses were focused on that species. Statistical analysis showed that the abundance of Ae. albopictus was best described by a linear regression model including a regional effect $\left(\mathrm{F}=62.00, \mathrm{df}=7.58, \mathrm{p}<2.2 \times 10^{-16}\right)$ and a period effect $\left(\mathrm{F}=36.22, \mathrm{df}=3.58, \mathrm{p}=2.548 \times 10^{-13}\right)$ (Table 4). There was an increasing abundance in sequential order Haute Matsiatra, Amaoron'I Mania, Menabe, Boeni, Diana, Analamanga, Vatovavy Fitovinany, and Antsinanana, whereas less Ae. albopictus was captured from July to September and April to June, that corresponded to more dry season, than from January to March and October to December (Table 5). There was no significant variation of Ae. albopictus from year to year during the study period (Table 6).

\section{Phylogenetic analysis of Aedes albopictus}

The sequences of two genes (449 bp for ND5 and 597 bp for $C O I$ ) were obtained from 80 Ae. albopictus (5 females and 5 males for each site) and were aligned with similar sequences retrieved from the Genbank database (Figure 3). The alignment revealed substitutions consisted of both transitions and transversions (not shown). The tree built from concatenated sequences (1046 bp) identified two

Table 3 Abundance of Aedes aegypti in sampling regions.

\begin{tabular}{|c|c|c|c|c|c|c|c|c|c|c|c|}
\hline \multirow{2}{*}{$\begin{array}{l}\text { Species } \\
\text { MonthsRegions }\end{array}$} & \multicolumn{11}{|c|}{ Aedes aegypti numbers* } \\
\hline & $\begin{array}{l}\text { Oct-Dec } \\
(2007)\end{array}$ & $\begin{array}{l}\text { Jan-Mar } \\
(2008)\end{array}$ & $\begin{array}{l}\text { Avr-Jun } \\
(2008)\end{array}$ & $\begin{array}{l}\text { Jul-Sept } \\
\text { (2008) }\end{array}$ & $\begin{array}{l}\text { Oct-Dec } \\
(2008)\end{array}$ & $\begin{array}{l}\text { Total2007- } \\
2008\end{array}$ & $\begin{array}{l}\text { Jan-Mar } \\
\text { (2009) }\end{array}$ & $\begin{array}{l}\text { Avr-Jun } \\
(2009)\end{array}$ & $\begin{array}{l}\text { Jul-Sept } \\
\text { (2009) }\end{array}$ & $\begin{array}{l}\text { Oct-Dec } \\
(2009)\end{array}$ & Total2009 \\
\hline Analamanga & 0 & 0 & 0 & 0 & 0 & 0 & 0 & 0 & 0 & 0 & 0 \\
\hline Amoron'i Mania & 0 & 0 & 0 & 0 & 0 & 0 & 0 & 0 & 0 & 0 & 0 \\
\hline Haute Matsiatra & 0 & 0 & 0 & 0 & 0 & 0 & 0 & 0 & 0 & 0 & 0 \\
\hline Antsinana & 0 & 0 & 0 & 0 & 0 & 0 & 0 & 0 & 0 & 0 & 0 \\
\hline Boeny & 10 & 6 & 4 & 0 & 6 & 26 & 15 & 0 & 0 & 8 & 23 \\
\hline Menabe & 20 & 11 & 3 & 2 & 17 & 53 & 22 & 2 & 5 & 13 & 42 \\
\hline $\begin{array}{l}\text { Vatovavy } \\
\text { FitovinanY }\end{array}$ & 0 & 0 & 0 & 0 & 0 & 0 & 0 & 0 & 0 & 0 & 0 \\
\hline Diana & 32 & 24 & 7 & 9 & 27 & 99 & 31 & 7 & 6 & 28 & 72 \\
\hline Total & & & & & & 178 & & & & & 137 \\
\hline
\end{tabular}

Data are grouped per three-months sampling period. *Aedes aegypti numbers corresponded to the total of wild adults collected from the field, no immature stages were recorded. 
Table 4 Best linear models for Aedes albopictus abundance according to the AICc.

\begin{tabular}{lllll}
\hline Model & $\mathbf{n}$ & $\mathbf{k}$ & AICc & $\Delta$ AICc \\
\hline Sqrt(AA) Site + Period + Year & 69 & 13 & 339.80 & \\
Sqrt(AA) $\sim$ Site + Period & $\mathbf{6 9}$ & $\mathbf{1 2}$ & $\mathbf{3 4 0 . 8 2}$ & $\mathbf{1 . 0 2}$ \\
Sqrt(AA) $\sim$ Site + Period + Year + AE & 69 & 14 & 342.16 & 2.35 \\
Sqrt(AA) $\sim$ Site + Period + AE & 69 & 13 & 342.85 & 3.05 \\
Sqrt(AA) $\sim$ Site*Year + Period & 69 & 20 & 347.82 & 8.02 \\
\hline
\end{tabular}

The retained model is in bold. AA stands for Ae. albopictus (abundance), AE for Ae. aegypti (presence/absence), $\mathrm{n}$ for sample size (three outliers were removed) and $\mathrm{k}$ for the number of parameters. Only the five best models are shown but all possible models (i.e., with all variable numbers and combinations) were built.

well-defined groups (Figure 3), with a strong support bootstrap value (84\%). One group consisted of specimens from South America (Brazil) and South-Asia (Cambodia, Thailand, Vietnam), and the other clustered all the sequences from Madagascar together with those of the Indian Ocean (La Reunion), North America (USA and Hawaii) and Europe (France). In Madagascar, the data of COI and ND5 separately (not shown) or concatenated (Figure 3 ) did not cluster Ae. albopictus specimens according to neither geographical location nor urban, suburban and sylvatic habitats. For example, individuals from Montagne d'Ambre forest (North West) were not distinguishable from those collected in Toamasina city (Eastern plains) or Ankazobe village (Highlands). As females have a dispersal behaviour driven by the search for oviposition sites, which are in turn influenced by natural or domestic environments, a phylogenetic analysis was performed according to sex. However, similar tree topologies were obtained (not shown). Sequences were intermixed between individuals sampled in contrasted ecological niches (bamboos, bushes, fruit trees, containers, tires etc.).

Table 5 Selected linear regression model to describe Aedes albopictus abundance: parameters.

\begin{tabular}{lllll}
\hline Variable & $\boldsymbol{\beta}^{\mathbf{a}}$ & $\mathbf{S E}^{\mathbf{b}}$ & $\begin{array}{l}\mathbf{9 5 \%} \mathbf{C l}^{\mathbf{c}}(\boldsymbol{\beta}) \\
\mathbf{m i n}\end{array}$ & $\mathbf{m a x}$ \\
\hline Intercept & 3.27 & 1.01 & 1.29 & 5.25 \\
Site ANA & 12.29 & 1.19 & 9.96 & 14.61 \\
Site ANT & 17.42 & 1.33 & 14.81 & 20.02 \\
Site BOE & 6.59 & 1.19 & 4.26 & 8.91 \\
Site DIA & 6.83 & 1.19 & 4.50 & 9.15 \\
Site HAU & -1.38 & 1.19 & -3.70 & 0.95 \\
Site MEN & 2.68 & 1.19 & 0.35 & 5.00 \\
Site VAT & 15.48 & 1.19 & 13.16 & 17.81 \\
Period JM & 5.97 & 0.91 & 4.20 & 7.75 \\
Period JS & 0.05 & 0.91 & -1.72 & 1.83 \\
Period OD & 6.62 & 0.82 & 5,01 & 8.23 \\
\hline a Paramer esin
\end{tabular}

a Parameter estimation; ${ }^{\mathrm{b}}$ Standard error; ${ }^{\mathrm{c}}$ Confidence interval. JM, January to March. JS, July to September. OD, October to December
Table 6 Models to describe Aedes albopictus abundance with simple effects.

\begin{tabular}{|c|c|c|c|c|c|c|}
\hline model & $\mathrm{n}$ & $k$ & $F$ & $\begin{array}{l}\text { df (model; } \\
\text { error) }\end{array}$ & $\mathbf{P}$ & AICc \\
\hline $\begin{array}{l}\text { sqrt(AA) } \\
\text { Region }\end{array}$ & 72 & 9 & 11.31 & $(7 ; 64)$ & $3.11 \times 10^{-}$ & 1006.63 \\
\hline sqrt(AA) Area & 72 & 6 & 14.35 & $(4 ; 67)$ & $\frac{1.63 \times 10^{-}}{8}$ & 1012.43 \\
\hline sqrt(AA) Period & 72 & 5 & 4.23 & $(3 ; 68)$ & 0.008 & 1042.28 \\
\hline $\operatorname{sqrt}(\mathrm{AA}) \sim \mathrm{AE}$ & 72 & 3 & 4.85 & $(1 ; 70)$ & 0.03 & 1045.23 \\
\hline sqrt(AA) Year & 72 & 3 & 0.01 & $(1 ; 70)$ & 0.91 & 1050.04 \\
\hline
\end{tabular}

AA stands for Ae. albopictus (abundance), AE for Ae. aegypti (presence/ absence), $\mathrm{n}$ for sample size (three outliers were removed) and $\mathrm{k}$ for the number of parameters.

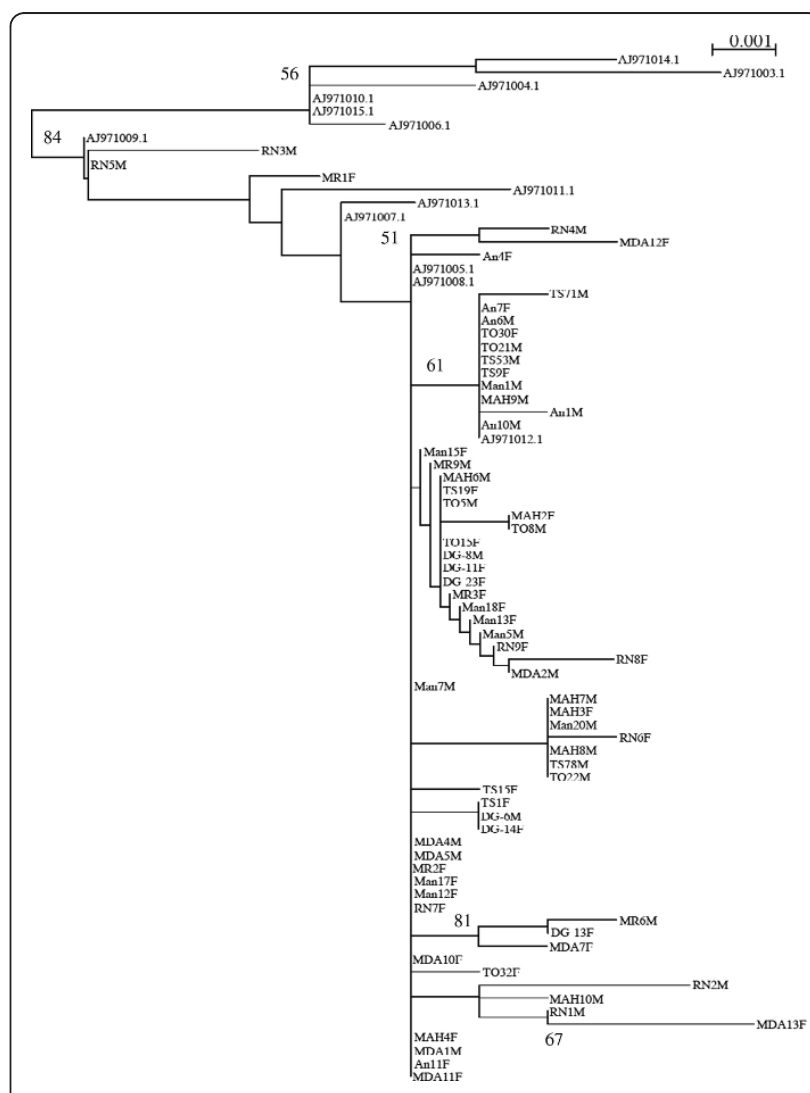

Figure 3 Phylogeny inference from concatenated $\mathrm{COI}$ and ND5 genes of Aedes albopictus by the maximum likelihood (ML) method based on the general time reversible (GTR) model. Percentage bootstrap supports (1000 replicates) superior to $50 \%$ are given at each node. Branch lengths represent estimated substitutions per site. Code sequence is as follows: An (Ankazobe), DG (Diego-Suarez), MAH (Mahajanga), Man (Mananjary), MDA (Montagne d'Ambre), MR (Morondava), RN (La Réunion), TO (Toamasina), TS (Tsimbazaza). Sequences retrieved from Genbank belonged to specimens from Brasil (AJ971003.1 and AJ971014.1), Vietnam (AJ971004.1 and AJ971010.1), Thailand (AJ971015.1), Cambodia (AJ971006.1), France (AJ971009.1 and AJ971008.1), Hawai (AJ971011.1), USA (AJ971005.1), La Reunion (AJ971013.1 and AJ971012.1), and Madagascar (AJ971007.1). 


\section{Vector competence}

Among eggs of the 13 Ae. albopictus populations transported from Madagascar to France, only six successfully hatched and gave adults for vector competence testing. The susceptibility of each population to infection was evaluated using artificial infectious CHIKV blood-meal. Overall, from a total of 1018 females tested in two trials, 1005 individuals (98.7\%) were diagnosed positive as measured by IFA on head squashes (Table 7). No fluorescent signal was found in mosquitoes engorged with non-infectious blood-meal as expected. At the population level, the disseminated infection rate ranged from 94 to $100 \%$.

\section{Discussion}

The survey conducted throughout two years in 15 localities among eight regions of Madagascar revealed that the distribution of Ae. albopictus and Ae. aegypti has changed considerably, in comparison to previous recorded distribution. Initially, the two species have been reported to be mainly allopatric with contrasted distribution $[1,2]$. Indeed, Ae. aegypti has been found to occupy mainly dry and semi-arid western and southern regions of Madagascar, whereas Ae. albopictus was dominant in eastern coast and highland areas $[1,2]$. Our data show that Ae. aegypti has become scarce within their previously delineated areas, and presently their population density is low. A decrease in Ae. aegypti distribution was also detected in the neighbour Reunion Island [16]. In addition, the remaining Ae. aegypti populations of Madagascar may have displaced to occupy several sylvatic areas: two in allopatry (Ankarana and Kirindy) and two in sympatry with Ae. albopictus (Montagne d'Ambre and Ranomafana). Ae. aegypti has been reported to occupy other forest areas on Indian Ocean Islands $[2,14]$. We also found two populations consisted of a few adults under bushes and fruit trees in Mahajanga city (western coast) and Diego Suarez city (north coast); which we suggest may be due to sporadic introduction by humans as this species was reported previously near the Ivato airport and in the south [2]. In contrast to its behaviour in South Asia [27], the species Ae. aegypti is less anthropophilic in Madagascar $[1,14]$, consequently it is thus conceivable to hypothesize that the smaller size of such populations will provoke the extinction of the species in domestic environments.

The population density of Ae. albopictus was higher compared to that of Ae. aegypti, and also its distribution was wider, covering the eight regions surveyed from west to east and in the north. This study confirms the extension of the distribution area of Ae. albopictus which was already reported [2,14]), albeit to a lesser extent. More evidence hereby was provided on the adaptation capabilities of $A e$. albopictus to occupy various eco-climatic regions of Madagascar, from the high altitude with temperate conditions prevalent in the highland region up to typical tropical conditions of the low altitude of the coastal regions. These data undoubtedly confirm the environmental plasticity of which Ae. albopictus is known to be capable of i.e. adaptation in contrasting environments. For instance, it was shown that Ae. albopictus has the ability to adapt to cold temperatures, and these adaptative capacities are likely due to its ability to synthesize a high amount of lipids which consequently can provide eggs with substantial yolk resources to maintain them through diapause [28-30].

Ae. albopictus was predominantly found in artificial environments which formed its major oviposition sites. These included dumped containers, used and abandoned tires and buckets, coconuts and bamboo cut trees, that allow for the persistence of small numbers of mosquitoes or eggs. The population density significantly increases at the rainy season, and differences were found between regions with a high abundance found in the east coast of Antsinanana. Though Ae. albopictus is known to be highly anthropophilic, specimens were also found in sympatry with Ae. aegypti in some wild areas. Surprisingly, Ae. albopictus also predominated in such conditions as well, suggesting a better competitiveness [31,32]. Although Ae. albopictus females have feeding preferences towards mammals, recent investigations highlighted the opportunistic and broad spectrum trophic behaviours to cold and other warm-blood vertebrates such as birds and reptiles [33,34]. Overall, these features suggest that the wide distribution and invasiveness of Ae. albopictus in Madagascar can be

Table 7 Disseminated infection rates of Aedes albopictus measured 14 days post-infection for CHIKV 06

\begin{tabular}{|c|c|c|c|c|c|c|}
\hline \multirow[t]{2}{*}{ Region } & \multirow[t]{2}{*}{ Locality } & \multirow[t]{2}{*}{ Breeding site } & \multicolumn{2}{|c|}{ Total engorged mosquitoes } & \multicolumn{2}{|c|}{ Total infected mosquitoes (\%) } \\
\hline & & & Trial $1^{*}$ & Trial $2^{*}$ & Trial1* & Trial2* \\
\hline Diana & Montagne d'Ambre & Forest, tree holes & 74 & 80 & $73(98.6)$ & $80(100)$ \\
\hline \multirow[t]{3}{*}{ Atsinanana } & Toamasina city & Old tires & 76 & 77 & $75(98.7)$ & $73(94.8)$ \\
\hline & & Coconut & 90 & 89 & $89(98.9)$ & $89(100)$ \\
\hline & & Buckets abandoned & 96 & 98 & $94(97.9)$ & $97(98.9)$ \\
\hline \multicolumn{2}{|c|}{ Analamanga Ankazobe } & Old tires & 84 & 80 & $83(98.8)$ & $79(98.7)$ \\
\hline \multicolumn{2}{|c|}{ Tsimbazaza } & Bamboo hedge & 83 & 91 & $83(100)$ & $90(98.9)$ \\
\hline
\end{tabular}

* Trial 1 was performed with generations F2 or F3, whereas trial 2 with F4 or F5 
attributed to their adaptive behaviour to both abiotic and biotic environmental factors, including resistance to agrochemicals $[35,36]$.

To examine whether the environment inhabited by mosquitoes generated genetic structuring amongst these populations, a phylogenetic analysis was performed using COI and ND5 mitochondrion markers [25]. The haplotype sequences of Ae. albopictus from Madagascar were clearly separated from those from South America (Brazil) and South Asia (Cambodia, Thailand, Vietnam). However, no significant differences were found between sylvan and domestic populations of Madagascar. Malagasy populations of Ae. albopictus were intermixed with individuals from the Indian Ocean (La Reunion Island), Europe (Normandie, France), and North America (Jacksonville, USA). These results may suggest a recent invasion process or a trade-off between these regions.

Experimental infections of six Malagasy Ae. albopictus populations with CHIKV 06.21, a strain that circulated in the Indian Ocean [8], demonstrated their high susceptibility to infection. This high susceptibility has already been reported for this CHIKV strain 06.21 in most $A e$. albopictus populations from the Indian Ocean [9], and was attributed to an A- $>\mathrm{V}$ amino acid substitution at position 226 in the viral E1 glycoprotein (8), leading to efficient dissemination and transmission by the vector $[9,37]$.

\section{Conclusions}

Based on the current data and those obtained in previous investigations (1980s), it is clear that Ae. albopictus is spreading and increasing its density in Madagascar since its introduction from Southeast Asia. Concurrent with this expansion, Ae. aegypti has become very scarce. Changes in this biogeographical pattern are probably linked to intensive destruction of natural forests through accelerated urbanization and rapid anthropization. The increasing density of Ae. albopictus throughout different areas of the country and its susceptibility towards both chikungunya and dengue (5), strongly suggest that this species can be implicated as the main vector in recent outbreaks of these two arboviruses. Thus, reinforcing surveillance and implementing control measures against this invading species are needed in Madagascar. Additionally, further surveillance to monitor the biogeography of other potential mosquito vector genera such as Culex, Mansonia, and Erethmapodites which are usually associated with man-made environments is recommended.

\section{Acknowledgements}

We are grateful to Madagascar National Parks (formely ANGAP) for authorizing the collection of wild mosquitoes. We thank the National Reference Center of Arboviruses at the Institut Pasteur in Paris for providing the CHIKV 06.21 strain. We would also like to thank the anonymous reviewers for their critical assessment of our work. FNR was supported by the Fondation pour la Recherche sur la Biodiversité (FRB, formely IFB). This work was funded by the grant FRB-CD-AOOI-07-012, and was carried out within the frameworks of GDRI "Biodiversité et Développement Durable à Madagascar" and COST action F0701 "Arthropod Symbioses: from fundamental to pest disease management".

\section{Author details}

1UMR CNRS 5557 Ecologie Microbienne, Université Lyon 1, 43 boulevard du 11 Novembre 1918, Villeurbanne cedex 69622, France. Département d'Entomologie, de la Facultés des Sciences d'Antananarivo, Antananarivo, Madagascar. ${ }^{3}$ Centre National de Recherche sur l'Environnement, Antananarivo, Madagascar. ${ }^{4}$ Institut Pasteur, Département de Virologie, Laboratoire Arbovirus et Insectes Vecteurs, Paris, France. ${ }^{5}$ CNRS; UMR 5558, Laboratoire de Biométrie et Biologie Evolutive, Université Lyon 1, Université de Lyon, Lyon, Villeurbanne F-69622, France. ${ }^{\circ}$ Laboratoire Arbovirus et Insectes Vecteurs, Institut Pasteur, Paris, France.

\section{Authors' contributions}

FNR managed mosquito sampling with other Malagasy members (LHR, PR, LSR). FNR, VTV, KZ, CVM, LM, ABF, PM designed and performed experiments. FNR, BOR, EH, PM

analyzed the results. FNR, BOR, PM wrote the paper in collaboration with other authors. All authors read and approved the final version of the manuscript

\section{Competing interests}

The authors declare that they have no competing interests.

Received: 30 August 2011 Accepted: 20 March 2012

Published: 20 March 2012

\section{References}

1. Ravaonjanahary C: Les Aedes de Madagascar. Travaux et documents de I'ORSTOM 1978, France.

2. Fontenille D, Rodhain F: Biology and distribution of Aedes albopictus and Aedes aegypti in Madagascar. J Am Mosa Control Assoc 1989, 5:219-225.

3. Reiter P, Fontenille D, Paupy C: Aedes albopictus as an epidemic vector of Chikungunya virus: another emerging problem? Lancet Infect Dis 2006, 6:463-464.

4. Delatte H, Dehecq JS, Thiria J, Domerg C, Paupy C, Fontenille D: Geographic distribution and developmental sites of Aedes albopictus (Diptera: Culicidae) during a chikungunya epidemic event. Vector Borne and Zoonotic Dis 2007, 7:1-11.

5. Delatte H, Paupy C, Dehecq JS, Thiria J, Failloux A-B, Fontenille D: Aedes albopictus, vector of chikungunya and dengue in La Réunion: biology and control. Parasite 2008, 15:3-13.

6. Zeller HG: Dengue, arbovirus and migrations in the Indian Ocean. Bull Soc Pathol Exot 1998, 91:56-60

7. Halstead SB: Dengue virus-mosquito interactions. Annu Rev Entomol 2008, 53:273-291.

8. Schuffenecker I, Iteman I, Michault A, et al: Genome microevolution of chikungunya viruses causing the Indian Ocean outbreak. PLoS Med 2006, 3:e263.

9. Vazeille M, Moutailler S, Coudrier D, et al: Two chikungunya isolates from the outbreak of La Reunion (Indian Ocean) exhibit different patterns of infection in the mosquito Aedes albopictus. PLoS One 2007, 2:e1168.

10. Renault P, Solet JL, Sissoko D, Balleydier E, Larrieu S, Filleul L, Lassalle C, Thiria J, Rachou E, de Valk H, llef D, Ledrans M, Quatresous I, Quenel P, Pierre $\mathrm{V}$ : A major epidemic of chikungunya virus infection on Reunion Island, France, 2005-2006. Am J Trop Med Hyg 2007, 77:727-731.

11. Ratsitorahina M, Harisoa J, Ratovonjato J, et al: Outbreak of dengue and Chikungunya fevers, Toamasina, Madagascar. Emerg Infect Dis 2008, 14:1135-1137.

12. Sang RC, Ahmed O, Faye O, et al: Entomologic investigations of a chikungunya virus epidemic in the Union of the Comoros, 2005. Am J Trop Med Hyg 2008, 78:77-82.

13. Randrianasolo L, Raoelina $Y$, Ratsitorahina M, Ravolomanana L, Andriamandimby S, Heraud JM, Rakotomanana F, Ramanjato R, RandrianarivoSolofoniaina $A E$, Richard V: Sentinel surveillance system for early outbreak detection in Madagascar. BMC Public Health 2010, 10:31. 
14. Zouache K, Raharimalala FN, Raquin V, Tran-Van V, Raveloson Ravaomanarivo LH, Ravelonandro P, Mavingui P: Bacterial diversity of fieldcaught mosquitoes, Aedes albopictus and Aedes aegypti, from different regions of Madagascar. FEMS Microbiol Ecol 2011, 75:377-389.

15. Salvan M, Mouchet J: Aedes albopictus and Aedes aegypti at lle de la Reunion. Ann Soc Belg Med Trop 1994, 74:323-326.

16. Bagny L, Delatte H, Quilici S, Fontenille D: Progressive decrease in Aedes aegypti distribution in Reunion Island since the 1900s. J Med Entomol 2009, 46:1541-1545.

17. O'Meara GF, Evans LF Jr, Gettman AD, Cuda JP: Spread of Aedes albopictus and decline of Ae. aegypti (Diptera: Culicidae) in Florida. J Med Entomol 1995, 32:554-562.

18. Kamgang B, Brengues C, Fontenille D, Njiokou F, Simard F, Paupy C: Genetic structure of the tiger mosquito, Aedes albopictus, in Cameroon (Central Africa). PloS One 2011, 6:e20257.

19. Higgs S: The 2005-2006 Chikungunya epidemic in the Indian Ocean. Vector Borne Zoonotic Dis 2006, 6:116-116.

20. Mousson L, Martin E, Zouache K, Madec Y, Mavingui P, Failloux A-B: Wolbachia modulates Chikungunya virus replication in Aedes albopictus. Mol Ecol 2010, 19:1953-1964.

21. Kuberski TT, Rosen $L$ : A simple technique for the detection of dengue antigen in mosquitoes by immunofluorescence. Am J Trop Med Hyg 1977, 26:533-537.

22. Zouache K, Voronin D, Tran-Van V, Mousson L, Failloux AB, Mavingui P: Persistent Wolbachia and cultivable bacteria infection in the reproductive and somatic tissues of the mosquito vector Aedes albopictus. PLoS One 2009, 4:e6388.

23. Kambhampati S, Smith PT: PCR primers for the amplification of four insect mitochondrial gene fragments. Insect Mol Biol 1995, 4:233-236.

24. Birungi J, Munstermann LE: Genetic structure of Aedes albopictus (Diptera: Cluicidae) populations based on mitochondrial ND5 sequences: Evidence for an independent invasion into Brazil and United States. Ann Entomol Soc Am 2002, 95:125-132.

25. Mousson L, Dauga C, Garrigues T, Schaffner F, Vazeille M, Failloux A-B: Phylogeography of Aedes (Stegomyia) aegypti (L.) and Aedes (Stegomyia) albopictus (Skuse) (Diptera:Culicidae) based on mitochondrial DNA variations. Genet Res 2005, 86:1-11.

26. Anderson DR, Burnham KP, White GC: AIC model selection in overdispersed captured-recapture data. Ecology 1994, 75:1780-1793.

27. Urdaneta-Marquez L, Failloux A-B: Population genetic structure of Aedes aegypti, the principal vector of dengue viruses. Infect Genet Evol 2011, 11:253-261.

28. Hawley WA: The biology of Aedes albopictus. J Am Mosq Control Assoc Supp/ 1988, 1:1-39.

29. Kobayashi M, Nihei N, Kurihara T: Analysis of northern distribution of Aedes albopictus (Diptera:Culicidae) in Japan by geographical information system. J Med Entomol 2002, 39:4-11.

30. Delatte $H$, Gimonneau G, Triboire A, Fontenille D: Influence of temperature on immature development, survival, longevity, fecundity, and gonotrophic cycles of Aedes albopictus, vector of chikungunya and dengue in the Indian Ocean. J Med Entomol 2009, 46:33-41.

31. Juliano SA, Lounibos LP, O'Meara GF: A field test for competitive effects of Aedes albopictus on A. aegypti is South Florida: differences between sites of coexistence and exclusion? Oecologia 2004, 139:583-593.

32. Benedict MQ, Levine RS, Hawley WA, Lounibos LP: Spread of the tiger: global risk of invasion by the mosquito Aedes albopictus. Vector Borne Zoonotic Dis 2007, 7:76-85.

33. Richards SL, Ponnusamy L, Unnasch TR, Hassan HK, Apperson CS: Hostfeeding patterns of Aedes albopictus (Diptera: Culicidae) in relation to avaibility of human and domestic animals in suburban landscapes of central North Carolina. J Med Entomol 2006, 43:543-551.

34. Delatte H, Desvars A, Bouétard A, Bord S, Gimonneau G, Vourc'h G, Fontenille D: Blood-feeding behaviour of Aedes albopictus, a vector of chikungunya on La Réunion. Vector Borne Zoonotic Dis 2010, 10:249-258.

35. Khan HAA, Akram W, Shehzad K, Shaalan E: First report of field evolved resistance to agrochemicals in dengue mosquito, Aedes albopictus (Diptera, Culicidae), from Pakistan. Parasites \& Vectors 2011, 4:146.

36. Kamgang B, Marcombe S, Chandre F, Nchoutpouen E, Nwane P, Etang J, Corbel V, Paupy C: Insecticide susceptibility of Aedes aegypti and Aedes albopictus in Central Africa. Parasites \& Vectors 2011, 4:79.
37. Tsetsarkin KA, Vanlandingham DL, McGee CE, Higgs S: A single mutation in chikungunya virus affects vector specificity and epidemic potential. PLOS Pathog 2007, 3:e201.

doi:10.1186/1756-3305-5-56

Cite this article as: Raharimalala et al:: Biogeography of the two major arbovirus mosquito vectors, Aedes aegypti and Aedes albopictus (Diptera, Culicidae), in Madagascar. Parasites \& Vectors 2012 5:56.

\section{Submit your next manuscript to BioMed Central and take full advantage of:}

- Convenient online submission

- Thorough peer review

- No space constraints or color figure charges

- Immediate publication on acceptance

- Inclusion in PubMed, CAS, Scopus and Google Scholar

- Research which is freely available for redistribution

Submit your manuscript at www.biomedcentral.com/submit
C Biomed Central 